\title{
Analysis on the Key Points of Influential Factors in Product Morphological Design
}

\author{
Juanling Guo ${ }^{1, \mathrm{a}}$, Kaining Meng ${ }^{1}$, Ying Meng ${ }^{1}$ \\ ${ }^{1}$ Xihua University, School of Art and Design, Chengdu, China
}

\begin{abstract}
For designing out high-tech products which can attract consumers and satisfy their demands, this paper has analysed the influencial factors of product morphological design. Firstly, the author used the principle of semiotics and man-machine engineering to analyse products systematically, to optimize the complex of "man-machine- environment", and then I studied the product's own factor, man-machine factor and external factor. In addition, this paper explains the influence factors in the product morphological design with examples. Moreover, the function and the form of product are ingeniously combined to improve the quality and connotation of the product. To sum up, this paper based on the theory of influential factors in product morphological design, proposed innovative thought, treat product morphological design from different perspectives, which will provide a reference for the later product design.
\end{abstract}

\section{Product morphological design}

Product morphological design is a media to convey information and the carrier for people to explore the world. Design could transform abstract ideas into perception and turn consciousness into cognitive state, which is keep changing and developing. As we all know, the product is designed to serve the society, so if we want to realize the perfect fusion of products and consumers, we cannot ignore the demand of the market. So we have to grasp the market's real needs and social relations. Product design shouldn't only depended on designers' intuition experience, but also links products' multiple functions and form systematically. Both of these include its own factors, man-machine factors and external factors. Designers need to systematically combines design, creation, process, production together, to make ideas integrate into products better. ${ }^{[1]}$ Design is a kind of culture and practice, it emphasis things' supposed states, so as to serve for people, solve problems in people's lives. People can perceive the products and have interaction with them. So as to keep improving people's life quality, make product worth it.

\section{Factors affecting morphological design}

The product is complemented by its structure, function, modeling and technology, as a relatively complex symbol system, its visual form is composed of line, color and volume. This kind of visual symbol has been found its value from the beginning of design, and it is designed into form code, then the code is put into practical

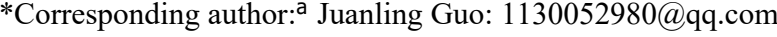

production. Finally, when consumers use it, they will decode the product and obtain the final impression of it. From the perspective of semiotics, this is product's own modelling factor, but product morphological design dosen't only influent its own factor, but man-machine factor and external factor also will influent product morphological design. Man-machine engineering is an interdiscipline, it doen't only optimize the single element, indeed, it optimize the "human - machine - environment" integration at the same time, to get the best design programme.

\subsection{Products own factors}

Product design is not as same as art design, so when design product's appearance, we can't take it as a work of art design, which only need consider its aesthetic value and artistic value. However, product's form is the carrier of product's function, they depend on one another. The meaning of product design is to achieve a union of form and function. Designers are supposed to combine product's appearance with its function, in order to satisfy users' function demand and to be innovative and beautiful. What's more, industrial production makes the design and processing of products possible, that is, the so-called "If you can design it, you can produce it."

First of all is to consider products' own factors, like structure, function, size, color, material and processing technology, etc. Surface processing technology can present many different visual effects. And product is not the purpose, but the means to achieve the goal. Qualified product design is not just the design of the exterior renderings, but to choose appropriate materials, 
reasonable structure, proper colour and finally make out a product that satisfy both of designers and users. Therefore, designers have to consider a lot when making selection. Any product is a system composed of various parts in a certain form. In which there are visible and invisible factors, visible factors like materials, visible structures, shapes; and invisible factors like invisible assembly forms, working principles and product performance.

\subsection{Human-computer factors of product}

Human sensory organs include the eyes, ears, nose, tongue, skin and limbs, which have different degrees of cognitive ability to the product, therefore, all of them should be considered in the design process. The design should reflect the values of "people-oriented", so it is necessary to fully consider the relationship between man and machine in the modeling, to accord with the cognitive psychology of people.

People's first impression of the product is most from the visual perception, so the designer tend to focuse on the visual effect firstly. Different product forms will give people different visual feelings and convey different meanings. For example, the product of curve modelling, give person round, soft, cosy visual feeling; the product of straight line modelling gives person modern, strong, grand visual feelings. Therefore, in the design process, it is necessary to excavate the visual characteristics of product and the meaning conveyed by the product form.

A good product should lighten the burden of hearing. In design, it is important to reduce the noise and protect people's hearing sense. During the design process, we'd better optimize the structure and study some new materials. For example, replace metal materials by some non-metallic materials, which can not only reduce vibration, but also absorb noise.

Products will be touched by people, so the place to be contacted, the control panel or the switch button must fit human's physiological characteristics. Although tactile sensation is not as sensitive as the visual and auditory senses, different material still give one person with different psychological feelings, such as wood products and wood-like products may have the same visual effect, but the tactile sense is not the same, and person will feel different.

Designers should also notice changes of smell. Take kitchen supplies as example, this kind of products with peculiar smell is easy to bring users rightly bad feeling. Products with bad experience feelings can affect consumers' purchasing desire. So designers are also supposed to be considerate when making choices of materials, had better choose non-polluted and odorless materials.

Using the same action for a long time will cause harm to people. Therefore, in the process of designing products, we should consider the man-machine relationship, movement, balance and body feeling. Design comfortable and appropriate structure to reduce the harm to person. To stand out in a variety of similar products, products must do well in every aspect. As people don't make choices only because of a single feature, every aspect including shape, color, sound, smell or material should be taken into consideration, and combined with people's real demand.

People obtain the impression of products through visual feeling mostly, they only care about products' appearance, color, and have little cognition of their function, material and durability features. Therefore, in the design process, designers also need to furtherly study how to present all the products' features to users.

As shown in the figure 1, a flying fish chair designed by the designer--Montreal, there is a new concept that is to install parallel wood strips on a rotating cylinder, allowing users to rotate the slats at will to get the most comfortable form. It can be a common chair, deck chair, sofa, or a sofa bed. The whole design used the light color series, and a large number of curve shape modeling reflects the product's round, soft and elegant features. Meanwhile, the wood material provided feelings of healthy 、 green and environmental. The overall form fully considers the human physiology factor, and it's versatile and innovative.

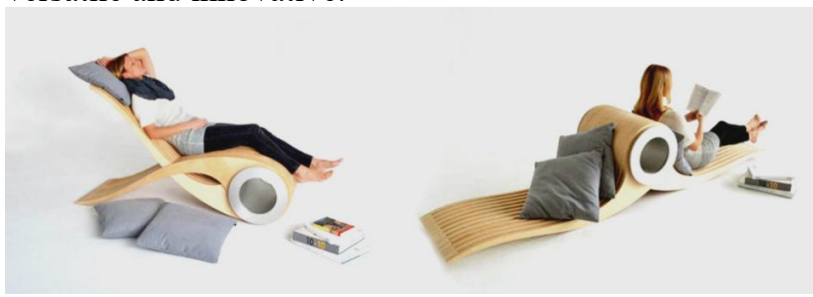

Fig 1. design of flying fish chair.

\section{External factors of the product}

The external factors of product morphological design doesn't only include relationship between the product and environment, but also national policy factor. Product's influence on the environment is reflected by whether the product will cause pollution and impact on the environment, and whether products will cause noise to the space, etc. Green design is what we're going to follow right now. Multifunctional design, portable design, detachable folding design and other designs can reduce the hazard on the environment.

From the aspect of national policy, we must attach importance to ecological construction and protect ecological environment, which was mentioned by $\mathrm{Xi}$ Jinping, the national general secretary, in the 19th people's congress. In the modern society with rapidly developing industrialization, it is everyone's responsibility and obligation to protect the ecological environment. We should base on ecological concept, design high-quality and ecological products. At the same time, the state should have a quality inspection standard for every kind of product, which must be obeyed in the design process. The product should be standardized instead of only pursuing innovation. During the design process, we must ensure that the product can pass the safety test so as to guarantee their safety, otherwise they can easily cause some damages, which violates the original intention of the design, that is to bring convenience to people instead of causing harm. 


\section{Conclusion}

The mainstream of the society is the integration of informatization and industrialization. Industrial design is one of the key links of "Made in China 2025". One of the key problems is to improve the innovative ability of products design

We need to consider product morphological design from many factors we mentioned below, to design out innovative products. In the Internet age, people's demands for healthy, quality life are constantly improving. People's life is closely connected with the development of information technology. Nowadays, a good design should have normal function, and meet futural pepole's demand of life style, product experience and potential taste, etc. The perception that "Design is about making things look good" has gone. In industry 4.0 , good design is not just about functional design, it should be the constant innovation of technology, design and users' experience, and consider problems from different angles, provide perfect service, excavate potential demand, design products that conform to the user's psychology, meet the increasing personalized requirements and improve product value.

\section{Acknowledgment}

Fund project. Major projects in Sichuan education department. (Item number:W171300); University-level graduate innovation fund project of Xihua University.(Item number:ycjj2017110).

\section{References}

1. Lin Liang. Analysis of ergonomic application points in product modeling design, V E,36 (2015) .

2. Zhang Linghao. Semantics of Products. Beijing: China Architecture \& Building Press, (2009).

3. $\mathrm{Xu}$ Bochu. Industrial Design Procedures and Methods. Beijing: People's Fine Arts Publishing House, 2010.

4. Tong Weilin. Analysis of the Three Elements of Product Design. QunWenDiDi, 23(2011).

5. Liu Jingyu. Conceptual Analysis of Product Appearance Design. M D, 02(2013).

6. Mao Weikang. Discussing industrial design changes under the concept of Industry 4.0. M D, 02(2016). 